\title{
Bilharzial Colonic Polyps: Case Presentation
}

\author{
Naglaa F Abd El-Latif ${ }^{1}$, Essam Saaed Bedewy ${ }^{2}$ \\ ${ }^{1}$ Department of Parasitology, Medical Research Institute, Alexandria University, \\ Egypt. \\ ${ }^{2}$ Department of Tropical Medicine, Faculty of Medicine, University of Alexandria, \\ Egypt
}

Corresponding Author Naglaa Fathi Abd ElLatif

Mobile:

$+201224110570$

E mail:

dr_naglaafathi@alexu. edu.eg

dr_naglaafathi@hotma il.com

Key words:

Schistosomiasis, colonoscopy, colonic polyps, ova
Background: Schistosomiasis is a contagion caused by intestinal and urinary blood trematodes affecting around 200 million people worldwide. Adult worms colonize human blood vessels for years, successfully escaping the immune system while excreting hundreds to thousands of eggs daily. The chronic infection can cause anemia, retarded growth, hepatosplenomegaly, neurological sequlae and even death. For Diagnosis of schistosomiasis, microscopic examination of human wastes as well as tissues remains the gold standard owing to the characteristic shape and size of the eggs.

Objective: to present a case of bilharzial polyps presented to endoscopy unit of the department of Tropical Medicine, Faculty

\section{INTRODUCTION}

Schistosomiasis is an important disregarded tropical disease in various parts of the world. It is caused by five species of pathogenic parasite Schistosoma, with S. mansoni being the most rampant [1].

WHO estimates around 243 million people needed schistosomiasis treatment in 2011. An important target of current control programs implemented by WHO is periodic, exhaustive population treatment with praziquantel, the only drug appropriate for effective mass treatment against various Schistosoma species. However, treatment debacles have been documented in recent years and it is not clear whether these are due to actual resistance or to new infections [2]. of Medicine, Alexandria University, Egypt for colonoscopy and mistaken for IBD with suspicious polypoidal transfromation versus malignant process.

Methodolgy: Snare polypectomy was done and tissues were sent for histopathological evaluation which revealed multiple fresh and calcified bilharzial ova seen in mucosa and submucosa.

Conclusion: This unusual long standing case will give us the chance to recall schistosomiasis, its occurrence as colon polyps, clinical presentation and means of management.

\section{Current status of schistosomiasis in Egypt}

The Egyptian Ministry of Health recorded that before the execution of mass antischistosomiasis campaign in 1996; the prevalence was $>30 \%$ in 168 villages, $20-30 \%$ in 324 villages and $10-20 \%$ in 654 villages. By the end of 2010, the prevalence was more than $3.5 \%$ in only 20 villages while none had pervasiveness more than $10 \%$ in the whole country. The success in controlling Schistosomiasis in Egypt is accomplished through pursuance of WHO adopted control programs [3].

The aim of this work was to present a case of bilharzial polyps presented to endoscopy unit of the department of Tropical Medicine, Faculty of Medicine, Alexandria University, Egypt for colonoscopy and mistaken 
for IBD with suspecious polypoidal transfromation versus malignant process.

\section{PATIENT, MATERIAL AND METHODS}

53 years old male patient, working as gatekeeper, used to be a fisherman, till he quitted 10 years ago, born and living in Alexandria, Costal governorate in Egypt, Suffering from abdominal pain, diarrhea and easy fatigue since 5 months (December 2019), the pain was colicky, mainly in the hypogastrium and Diarrhea was scanty with mucous and no visible blood.

Past history: The patient suffered of several dysenteric attacks \& diagnosed as schistosoma, received praziquantel twice more than 10 years ago.

Complete blood count (CBC) was done and showed severe anemia with mild thrombocytopenia ( $\mathrm{Hb}: 5.8 \mathrm{~g} / \mathrm{dl}$, platelets 130 $000 / \mathrm{cmm}$ )

He was admitted to hospital and received packed RBC's transfusions. CBC after transfusions: ( $\mathrm{Hb}$ : $10.5 \mathrm{~g} / \mathrm{dl}$, WBC'S:4.9 /cmm, Platlets: 150 $000 / \mathrm{cmm}$ )

U/S abdomen showed Shrunken liver with periportal fibrosis, Dilated portal vein and Splenomaegaly $(21.5 \mathrm{~cm})$
Bone marrow aspirate revealed hypercellular pattern probably due to hypersplenism. Virology for $\mathrm{HCV}$ and $\mathrm{HBV}$ were negative. Upper G.I.T endoscopy was done and showed portal hypertensive gastropathy.

Stool analysis was Free, Schistosomal $\mathrm{Ag}$ (Circulating Cathodic Antigen (CCA) UrineTest) in urine was negative while Antischistosomal antibodies by indirect haemagglutination test (IHAT) was positive (1/1280).

The patient was treated with praziquantel in a dose of $40 \mathrm{mg} / \mathrm{kg}$ per day orally for one day in two divided doses. Two months later, CBC was repeated and again there was Hypochromic microcytic anemia ( $\mathrm{Hb}$ dropped to $8 \mathrm{mg} / \mathrm{dl}$ ) which was not fully expalined by hypersplenism.

Colonoscopy revealed multiple variable sized polyps extending from distal colon up till anal canal $(35 \mathrm{~cm}$ from the anal verge) condensed mainly at recto-anal region, colonic mucosa was markedly inflamed and ulcerated. (Figure 1)

Large polyps were removed using hot snaring technique and sent for histopathological assessment. The latter showed multiple colonic polypi lined by mucous secreting columnar epithelium with goblet cells and multiple fresh and calcified bilharzial ova in the mucosa and submucosa with surrounding granulomas and eosinophil rich inflammatory cellular infiltrate. (Figure 2) 

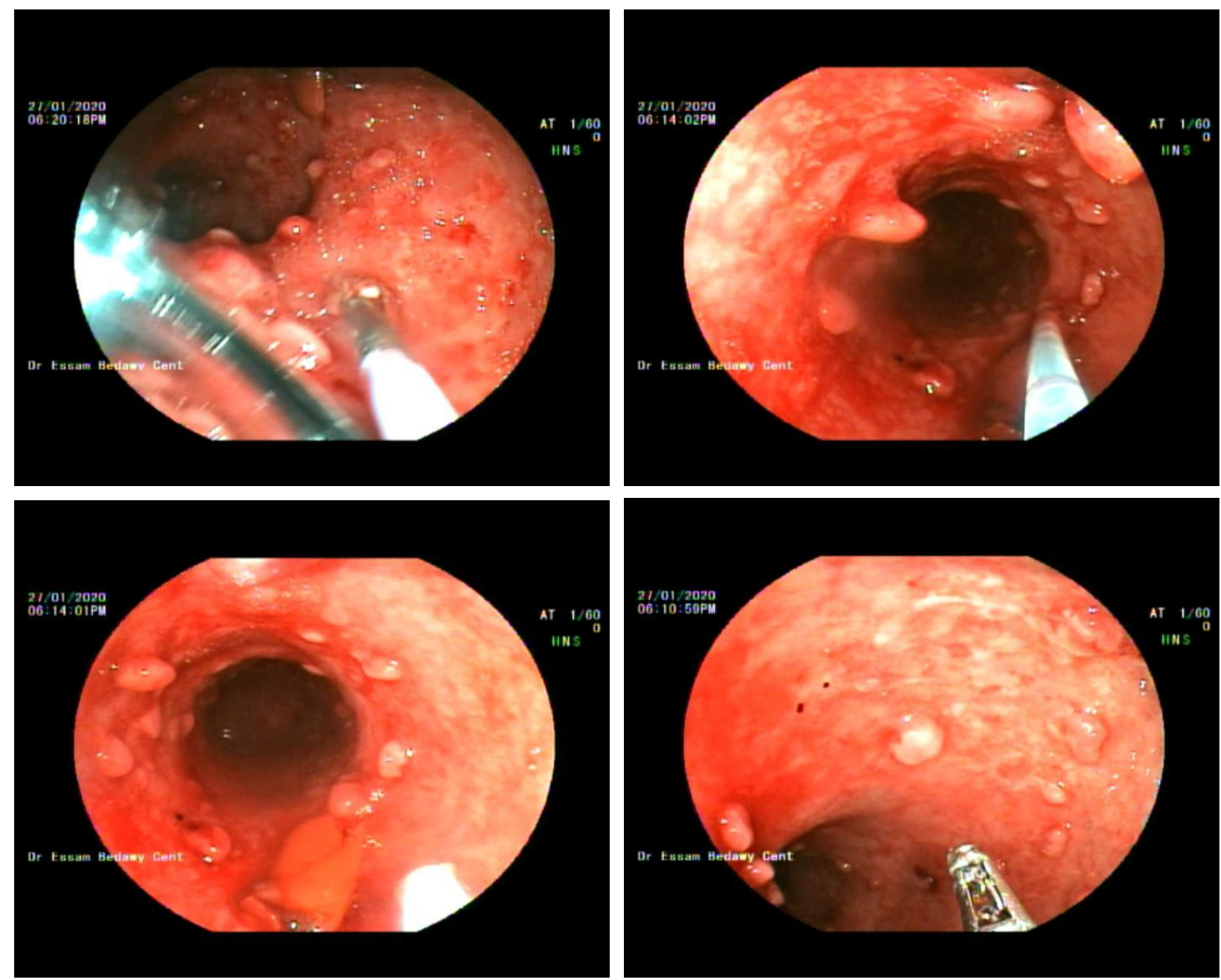

Figure 1: Multiple variable sized polyps and inflamed colonic mucosa.
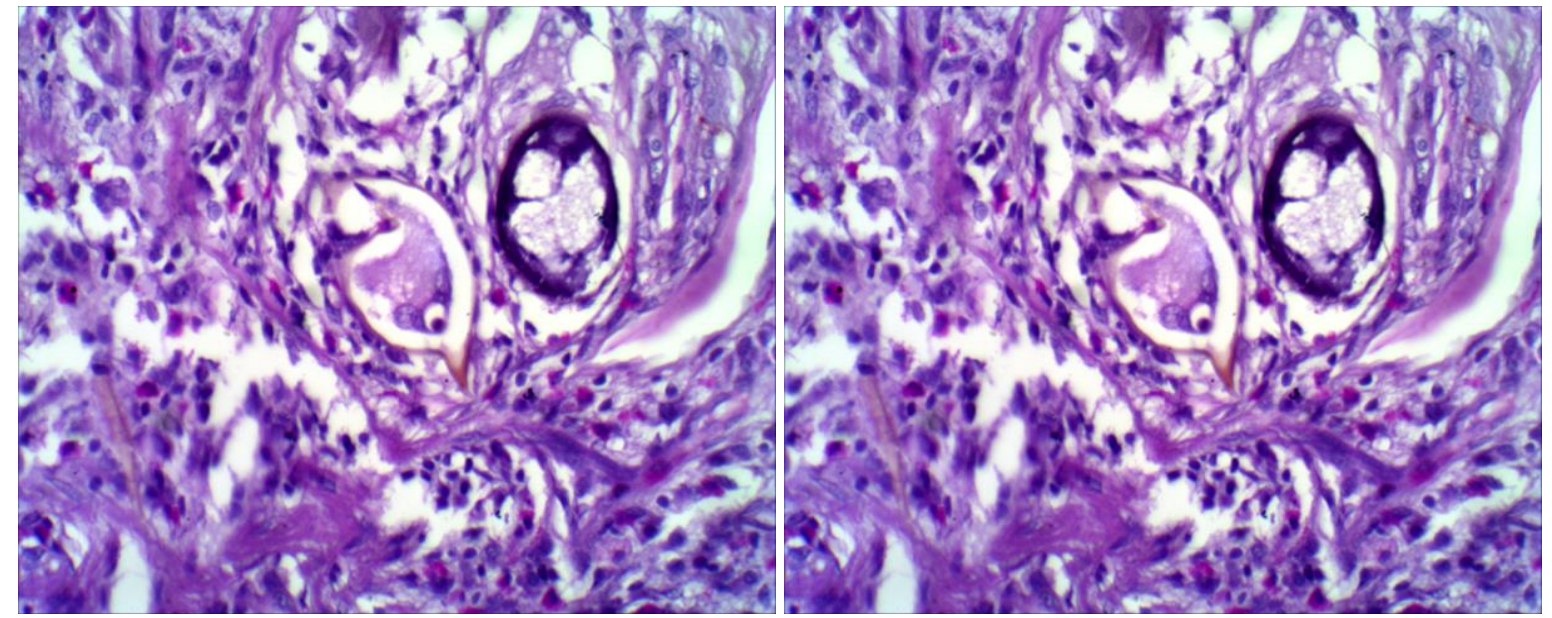

Figure 2: Multiple fresh and calcified bilharzial ova seen in mucosa and submucosa. 


\section{DISCUSSION}

The present case, the patient denied any exposure to fresh water source more than 10 years ago, he presented with hypochromic microcytic anemia in old age male which is considered red flag necessitated endoscopy. Colonoscopy revealed multiple polypi mistaken for IBD versus malignant process. Histopathology demonstrated fresh and calcified bilharzial ova. The case was confirmed as inflammatory bilharzial colitis with polyp formation despite he received praziquantel twice ten years ago (after been diagnosed as schistosomal) and once 2 months before biopsy.

Schistosoma eggs are viable, metabolically active organisms, and are highly antigenic unlike the adult worms which are less antigenic and can live for 5-10 years.

This patient had negative stool and CCA- urine tests. Despite high sensitivity of Schistosoma CCA test [4], detection of viable ova by microscopy of urine, feces and/or, tissue biopsies remains the gold standard for the diagnosis of schistosomiasis. Finally we recommend that treatment failure may need more than the recommended single day of treatment for extermination of parasites. For patients with signs of treatment failure including continuous symptoms, even when viable ova cannot be detected by coproscopic examination, repeated treatment should be considered until more precise methods for detection of persistent and/or active infection are available.

Ethical consideration: Consent was obtained from the case. All the information gathered from the patient was handled confidentially, and it was used only for research purpose.

Funding: None.

Conflict of interest: There is no conflict of interest.

\section{REFERENCES}

1. Utzinger J, N'Goran E K, Caffrey CR, Keiser J. From innovation to application: socialecological context,diagnostics, drugs and integrated control of schistosomiasis. Acta Tropica 2011; 120 Suppl 1:S121-37.

2. Wang W, Wang L, Liang YS. Susceptibility or resistance of praziquantel in human schistosomiasis: a review. Parasitology Research 2012; 111(5):1871-7.

3. Rashida M.R. Barakat.Epidemiology of Schistosomiasis in Egypt: Travel through Time: Review. Journal of Advanced Research 2013; 4(5): 425-432

4. Coulibaly JT, N'Gbesso YK, Knopp S, N'Guessan NA, Silue KD, van Dam GJ, et al. Accuracy of urine circulating cathodic antigen test for the diagnosis of Schistosoma mansoni in preschool-aged children before and after treatment. PLoS neglected tropical diseases. 2013; 7(3):e2109. 